\title{
Contrast during multiple schedules with different component response requirements
}

\author{
GEORGE R. KING and F. K. MCSWEENEY \\ Washington State University, Pullman, Washington
}

\begin{abstract}
Positive and negative behavioral contrast were examined when pigeons were required to keypeck in one component and treadle press in the other component of a series of multiple schedules. The experimental conditions were constructed so that the positive and negative contrast groups were exposed to complementary conditions. Positive keypeck and negative treadle-press contrast occurred in all subjects. Positive treadle-press contrast seemed to depend on the order of schedule presentation. Only one subject exhibited strong negative keypeck contrast. The results indicate that symmetrical conditions are not sufficient to produce positive and negative contrast for a given response when topographically different responses are used in the components of a multiple schedule. The results are globally consistent with the competition theory of behavioral contrast.
\end{abstract}

Multiple schedules of reinforcement involve the successive presentation of two simple schedules of reinforcement. Each simple schedule constitutes a component of the multiple schedule. During a standard behavioral contrast experiment, the reinforcement rate in one component (the variable component) is increased or decreased, and responding in the other, unchanged component is measured. Behavioral contrast is said to occur when there is an inverse relation between the response rates in the constant (unchanged) component and the reinforcement rates in the variable (changed) component. Positive contrast is an increase in the response rate in the constant component when the reinforcement rate in the variable component decreases. Negative contrast is a decrease in the response rate in the constant component when the reinforcement rate in the variable component increases (McSweeney \& Norman, 1979).

A critical question in the study of behavioral contrast is the extent to which contrast occurs in the same manner for different response topographies. In other words, can one mechanism explain the occurrence of behavioral contrast for all response topographies, as posited by Herrnstein (1970) and Staddon (1982; Hinson \& Staddon, 1978), or are multiple mechanisms required to describe the observation of contrast across responses of different topography (Rachlin, 1973)? Herrnstein stated that contrast is the result of changes in relative reinforcement rates, and Staddon stated that contrast is a result of the

The present experiment was based on a thesis submitted by G. R. King in partial fulfillment of the requirements for the Master of Science degree from Washington State University. The authors wish to express their gratitude for expert editorial comments by J. Higa, J. Hinson, A. W. Logue, H. Rachlin, and two anonymous reviewers on earlier versions of the paper. Preparation of the manuscript was supported by NSF Grant BNS 8416302 to $A$. W. Logue.

The first author is now at the State University of New York at Stony Brook. Please send reprint requests to: George R. King, Department of Psychology, SUNY at Stony Brook, Stony Brook, NY 11794. reallocation of interim responding (Staddon \& Simmelhag, 1971) to the component with the lower reinforcement rate. Both theories hold that positive and negative contrast are the result of one mechanism (i.e., changes in relative reinforcement rate or reallocation of interim responding) and, therefore, that contrast should occur in the same manner for all response topographies. Both Herrnstein and Staddon stated, however, that response topography affects the magnitude of contrast.

Rachlin (1973), however, stated that contrast occurs differently for different responses. When keypecking is the required response, positive and negative contrast occur by the addition or subtraction of elicited biological responses from the operant keypeck baseline. Keypecking is the elicited biological response when food or water is the reinforcer. When treadle pressing is the required operant, positive contrast should not occur readily, because the elicited keypecks would not add directly to the operant treadle-press baseline. Negative treadle-press contrast may occur because inhibited biological keypecks may produce an avoidance response to the key, which could move the organism away from the treadle and thereby lower the treadle-press response rate (negative contrast).

Some data suggest that positive and negative contrast are different for different responses. For example, several studies did not find positive treadle-press contrast under conditions that reliably produced positive keypeck contrast (Hemmes, 1973; McSweeney, 1978a; Westbrook, 1973). Furthermore, positive and negative keypeck contrast are inversely related to component duration (McSweeney, 1982), whereas positive and negative treadle-press contrast are directly related to component duration (McSweeney, 1982; McSweeney, Dougan, Higa, \& Farmer, 1986). It seems reasonable to argue that behaviors that change as different functions of an independent variable might be attributable to different mechanisms involved in producing contrast for the different responses (McSweeney et al., 1986). 
Given a situation involving keypecking in one component and treadle pressing in the other component of a multiple schedule, Herrnstein (1970) would predict that positive and negative contrast would occur for both responses and that the magnitude of positive and negative keypeck contrast would be larger than the magnitude of positive and negative treadle-press constrast. According to Staddon (1982), positive and negative contrast would occur for both responses. However, competition theory predicts that the magnitude of positive and negative treadle-press contrast would be larger than the magnitude of positive and negative keypeck contrast, because keypecking is more sensitive than treadle pressing to changes in reinforcement rate. Because keypecking is assumed to be more sensitive to changes in reinforcement rate, any change in the reinforcement rate for either response will result in a greater change in the keypeck response rate than in the treadle-press response rate, which should produce a greater reallocation of interim responding from the treadle-press to the keypeck component in the case of positive treadle-press contrast and a greater reallocation of interim responding from the keypeck to the treadle-press component in the case of negative treadle-press contrast. Rachlin's (1973) additivity theory predicts that positive and negative keypeck contrast would occur and that the magnitude of each would be approximately the same. Positive treadle-press contrast should not occur, because elicited, additive keypecks will not add directly to the operant treadle-press baseline response rate. Negative treadle-press contrast may occur if an avoidance response to the key develops during the negative contrast conditions.

This question has been examined in very few studies in which different instrumental responses produced reinforcers in the different components. Scull and Westbrook (1973, Experiment 1) failed to find positive keypeck contrast when barpressing was extinguished or positive barpressing contrast when keypecking was extinguished. Howard (1979) found positive keypeck contrast when barpressing was extinguished, but he did not extinguish keypecking to determine whether positive barpressing contrast would also occur. Furthermore, Howard failed to recover baseline reinforcement rates. Therefore, in Howard's experiment, behavioral contrast cannot be distinguished from fluctuations in responding over time. Overall, the results remain inconclusive concerning the existence of behavioral contrast in multiple schedules using different topographical responses with pigeons.

A second critical question in the study of behavioral contrast is whether negative contrast occurs under conditions that are opposite to those that produce positive contrast. In other words, will reversing the manipulations that produce positive contrast also produce negative contrast? Herrnstein's (1970) theory predicts that positive and negative contrast should be symmetrical because the expression of both positive and negative behavioral contrast is mediated by the same underlying mechanism: changes in relative reinforcement rates. McSweeney and Norman
(1979) and Schwartz (1975) argued that there is no logical reason why positive and negative contrast must be symmetrical.

Previous research occasionally has found one type of contrast under conditions that do not produce the other type of contrast (e.g., Ettinger \& McSweeney, 1981; Schwartz, 1975). For example, Schwartz found that the occurrence of negative keypeck contrast was independent of discriminative stimulus location, but that positive keypeck contrast would not occur unless the discriminative stimulus was located on the response manipulandum. Ettinger and McSweeney found that response rates during the water component of a food-water multiple schedule were lower (negative contrast) than response rates during the comparable component of a water-water multiple schedule, but that response rates during the food component of the food-water schedule were not higher than the response rates in the comparable component of a foodfood multiple schedule (absence of positive contrast). Other evidence, however, suggests that positive and negative contrast may be symmetrical for a given response.

As stated above, for a given response, positive and negative contrast exhibit the same functional relations across manipulations of an independent variable (McSweeney, 1982; McSweeney et al., 1986). These results indicate that positive and negative contrast are symmetrical for a given response, because similar manipulations of an independent variable produced complementary (i.e., symmetrical) effects on the expression of positive and negative contrast.

In the present study we assessed the symmetry of positive and negative behavioral contrast within and across response topographies while attempting to minimize the confounding variables of absolute reinforcement rates, reinforcement ratios, and component duration. We also attempted to determine whether it was possible to produce positive and negative contrast when different responses were used in the components of a series of multiple schedules. The two different instrumental responses employed in the components of the multiple schedules were keypecking and treadle pressing. The baseline multiple variable-interval (VI) 60-sec VI 60-sec schedule and 60sec component duration used here were selected as intermediate values to avoid favoring contrast for one response over the other. An examination of McSweeney (1978b, 1982 ) indicates that the selected baseline reinforcement rate and the component duration represent values that approximately cancel the opposing effects of these two variables for the two different responses.

A 4:1 reinforcement ratio between the components of the multiple schedule was used during all contrast phases in this experiment. A constant reinforcement ratio ensured that the positive and negative contrast phases were as symmetrical (i.e., complementary) as possible. Both Herrnstein (1970) and Staddon (1982) argued that the expression and magnitude of behavioral contrast is, in part, a function of the reinforcement rate delivered in the variable component. Consequently, a shift from mult VI $x$ 
VI $x$ to a mult VI $x$ extinction schedule (positive contrast) may not be comparable to a shift from a mult VI $x$ VI $x$ to a mult VI $x$ VI $y$, in which the VI $y$ is a higher reinforcement rate (negative contrast). Therefore, reinforcement rates in the variable component during the contrast conditions must be controlled to avoid a bias toward one type of contrast over the other. With a constant reinforcement ratio, differences in the observation of positive and negative contrast cannot readily be attributed to differences in the size of the change in the rates of reinforcement from the baseline to the contrast phases. In the absence of a scale of reinforcement, which would indicate what an organism perceived as equivalent changes in reinforcement contingencies (i.e., perceived as symmetrical), a constant, programmed reinforcement ratio is at present the best method of assessing the symmetry of positive and negative behavioral contrast (see, e.g., McSweeney et al., 1986 , for a similar argument).

\section{METHOD}

\section{Subjects}

Seven pigeons (numbers $5,17,18,2458,5964,83001$, and 83003 ), maintained at $80 \%$ of their free-feeding weights, served as subjects. Subjects 83001 and 83003 were experimentally naive. All other subjects had had experience in pecking keys for water and/or food reinforcers on multiple and concurrent schedules. No pigeon had had experience pressing treadles.

\footnotetext{
Apparatus

A standard three-key Grason-Stadler Model E6446C pigeon station, enclosed in a Grason-Stadler Model 25AA-300 soundattenuating chamber, was used. Two floor treadles were added to the enclosure. Each treadle was a 5.2-cm-diam aluminum disk held in a resting position $2.6 \mathrm{~cm}$ above the chamber floor by an aluminum strip. Each strip was $7.7 \mathrm{~cm}$ long and $1 \mathrm{~cm}$ wide, and entered the wall containing the magazine $16.8 \mathrm{~cm}$ below the outer response keys. The centers of the keys were approximately $19 \mathrm{~cm}$ apart, $8 \mathrm{~cm}$ from the side walls, and $18.4 \mathrm{~cm}$ above the chamber floor. Each key could be illuminated. The treadle required a force of approximately $.25 \mathrm{~N}$ to operate, the key required a force of approximately $.10 \mathrm{~N}$ to operate, and both response types produced a brief feedback click. A houselight, located in the upper right corner of the chamber, remained on during the session. A fan provided masking noise. Electromechanical equipment, located in another room, scheduled the experimental events.

\section{Procedure}

The naive subjects were first trained to eat from the food magazine. Subject 83001 was then trained to keypeck by an autoshaping procedure. Subject 83003 was trained to peck the left key by successive approximations because it did not respond to the autoshaping procedure. All pigeons were then trained to treadle press by an autoshaping procedure. This autoshaping procedure lasted three sessions, with 100 trials per session. During this procedure, the right light on the key located above the right treadle came on $8 \mathrm{sec}$ before the delivery of food. Food consisted of $5 \mathrm{sec}$ access to mixed grain. Lights and food were presented on a variable time 30-sec (VT 30-sec) schedule, constructed according to a procedure outlined by Catania and Reynolds (1968). Each pigeon was then placed on a VI 10-sec schedule until it exhibited a high, steady rate of treadle pressing.

The pigeons were assigned randomly to either the positive or the negative contrast group and then placed on a series of multiple sched-
}

Table 1

Schedules, in Order of Presentation, and the Number of Sessions That Each Subject Responded on Each Schedule

\begin{tabular}{ccc}
\multicolumn{1}{c}{ Schedule } & \multicolumn{2}{c}{$\begin{array}{c}\text { Number of Sessions } \\
\text { Each Subject Responded }\end{array}$} \\
\hline Postive Behavioral Contrast & Subject 2458 & Subject 18 \\
\hline mult VI 60-sec VI 60-sec & 36 & 40 \\
mult VI 60-sec VI 4-min & 29 & 36 \\
mult VI 60-sec VI 60-sec & 41 & 32 \\
mult VI 4-min VI 60-sec & 55 & 38 \\
mult VI 60-sec VI 60-sec & 24 & 57 \\
& Subject 5964 & Subject 05 \\
mult VI 60-sec VI 60-sec & 28 & 36 \\
mult VI 4-min VI 60-sec & 27 & 27 \\
mult VI 60-sec VI 60-sec & 40 & 46 \\
mult VI 60-sec VI 4-min & 41 & 45 \\
mult VI 60-sec VI 60-sec & 31 & 30 \\
Negative Behavioral Contrast & Subject 83001 & Subject 17 \\
\hline mult VI 60-sec VI 60-sec & 48 & 46 \\
mult VI 60-sec VI 15-sec & 35 & 33 \\
mult VI 60-sec VI 60-sec & 28 & 23 \\
mult VI 15-sec VI 60-sec & 28 & 40 \\
mult VI 60-sec VI 60-sec & 33 & 48 \\
mult VI 60-sec VI 60-sec & Subject 83003 & \\
mult VI 15-sec VI 60-sec & 27 \\
mult VI 60-sec VI 60-sec & 25 \\
mult VI 60-sec VI 15-sec & 80 & \\
mult VI 60-sec VI 60-sec & 19 & \\
\hline
\end{tabular}

ules. The multiple schedules, in order of presentation, and the number of sessions each subject was exposed to each schedule, are presented in Table 1. To control for order effects, different subjects responded on the schedules in different orders. The first component of the multiple schedule refers to the treadle-pressing component, and the second to keypecking. The multiple schedules were selected to maintain a 4:1 ratio of reinforcement rates during the contrast phases of the experiment (i.e., the second and fourth schedules listed in Table 1 for each subject).

A pigeon was exposed to each schedule until 5 days of stable responding had been obtained. Responding during a given schedule was considered stable when the response rates during the last five sessions fell within the range of response rates for all previous sessions of exposure to that schedule. In other words, the response rates in each component did not exhibit any new highs or lows during the last five sessions. Responding was considered stable only when the response rates in both components were stable.

Reinforcers for all schedules were delivered according to a procedure outlined by Catania and Reynolds (1968). Reinforcement consisted of $5 \mathrm{sec}$ access to mixed grain. When treadle pressing produced reinforcement, pigeons were required to press the treadle mounted below the right, red key for reinforcement. When keypecking produced reinforcement, the pigeons were required to peck to the left, blue key. Reinforcers that were not collected at the end of a component were canceled. During food delivery, both keylights were extinguished and no responses were recorded.

The components of the multiple schedules alternated every $60 \mathrm{sec}$ and were separated by a 3-sec time-out, during which the discriminative stimulus was turned off and no responses were recorded or reinforcers delivered. The 3-sec time-out was included so that the travel time between the manipulanda was not included in calculating the magnitude of contrast (McSweeney, 1982).

Sessions were conducted 6 or 7 days per week. Baseline sessions (mult VI 60-sec VI 60-sec) terminated after 30 reinforcers. Positive contrast sessions (mult VI 60-sec VI 4-min and mult VI 4-min 
VI 60-sec) terminated after 19 reinforcers. Negative contrast sessions (mult VI 60-sec VI 15-sec and mult VI 15-sec VI 60-sec) terminated after 75 reinforcers for all pigeons except Subject 83003. Sessions for this subject terminated after 50 reinforcers because satiation occurred with 75 reinforcers. These different criteria for terminating sessions ensured that session durations would remain approximately constant across conditions.

\section{RESULTS}

Absolute response rates, in responses per minute, were calculated by dividing the number of responses emitted during a component by the time the component was in effect. The time that the food magazine was present was omitted from all calculations. The mean rates of responding of the last five sessions for each component of each multiple schedule are presented in Table 2 . Treadle pressing is always the first schedule listed in Table 2.

Figure 1 presents the size of positive keypeck contrast over the last five sessions that a contrast schedule (i.e., the second and fourth schedules for each subject in $\mathrm{Ta}$ ble 1) was in effect. The size of contrast is expressed as a percentage deviation from the surrounding baseline schedules. This method of assessing contrast is consistent with McSweeney (1978a, 1982; McSweeney et al., 1986) and partially compensates for fluctuations over time and for the fact that baseline response rates are rarely perfectly recovered.

Points falling above the horizontal line constitute positive behavioral contrast. The point falling below the horizontal line indicates negative induction, defined as a decrease in response rates in the constant component fol- lowing decreases in the reinforcement rate in the variable component (McSweeney, 1982).

Table 2 and Figure 1 indicate that positive keypeck contrast occurred. Nineteen of 20 points for individual subjects and 5 of 5 points for the mean of all subjects fell above the horizontal line and constitute positive contrast. A sign test (Siegel, 1956) using the 4 individual subjects' points for the last five sessions the schedule was in effect is significant $(x=1, n=20, p<.0005)$.

Figure 2 represents the size of positive treadle-press contrast over the last five sessions that the mult VI $60-\mathrm{sec}$ VI 4-min schedule was in effect. The size of positive treadle-press contrast is expressed as a percentage deviation from baseline.

Table 2 and Figure 2 show that the observation of positive treadle-press contrast appears to have depended on the order of schedule presentation. For those subjects (Subjects 18 and 2458) that experienced the positive treadle-press contrast condition (mult Vi 60-sec VI 4-min) prior to the positive keypeck contrast condition (mult VI 4-min VI 60-sec), 10 of 10 points fell below the horizontal line (negative induction). For those subjects (Subjects 5 and 5964) that experienced the positive treadle-press condition after the positive keypeck contrast condition, 10 of 10 points fell above the horizonal line (positive contrast). A sign test performed using the individual subjects' points for the last five sessions the schedule was in effect was not significant $(x=10, n=20, p=.285$ ).

Figure 3 presents the size of negative treadle-press contrast over the last five sessions that the mult VI 60 -sec VI 15-sec schedule was in effect. The size of contrast is

Table 2

Mean Rates of Responding in Number of Presses per Minute Emitted During Each Component of Each Multiple Schedule

\begin{tabular}{|c|c|c|c|c|c|c|}
\hline \multirow[t]{3}{*}{ Subject } & \multirow[t]{3}{*}{ Response } & \multicolumn{5}{|c|}{ Component Schedules } \\
\hline & & \multicolumn{5}{|c|}{ Positive Behavioral Contrast } \\
\hline & & $\begin{array}{l}\text { VI 60-sec } \\
\text { VI 60-sec }\end{array}$ & $\begin{array}{l}\text { VI 60-sec } \\
\text { VI 4-min }\end{array}$ & $\begin{array}{l}\text { VI 60-sec } \\
\text { VI 60-sec }\end{array}$ & $\begin{array}{l}\text { VI 4-min } \\
\text { VI 60-sec }\end{array}$ & $\begin{array}{l}\text { VI } 60-\mathrm{sec} \\
\text { VI } 60-\mathrm{sec}\end{array}$ \\
\hline \multirow[t]{2}{*}{2458} & $\begin{array}{l}\text { Treadle press } \\
\text { Keypeck } \\
\text { Treadle press } \\
\text { Keypeck }\end{array}$ & $\begin{array}{r}29.0 \\
116.5 \\
8.4 \\
62.8\end{array}$ & \begin{tabular}{r|r|}
20.2 & \\
60.4 \\
8.4 \\
56.3
\end{tabular} & $\begin{array}{l}69.7 \\
81.5 \\
48.2 \\
51.3\end{array}$ & \begin{tabular}{r|}
36.3 \\
122.7 \\
16.7 \\
74.1
\end{tabular} & $\begin{array}{r}73.0 \\
107.2 \\
27.2 \\
50.0\end{array}$ \\
\hline & & $\begin{array}{l}\text { VI } 60-\sec \\
\text { VI } 60-\mathrm{sec} \\
\end{array}$ & $\begin{array}{l}\text { VI 4-min } \\
\text { VI 60-sec }\end{array}$ & $\begin{array}{l}\text { VI } 60-\sec \\
\text { VI } 60-\sec \\
\end{array}$ & $\begin{array}{l}\text { VI 60-sec } \\
\text { VI 4-min } \\
\end{array}$ & $\begin{array}{l}\text { VI } 60-\mathrm{sec} \\
\text { VI } 60-\mathrm{sec}\end{array}$ \\
\hline \multirow[t]{3}{*}{5964} & $\begin{array}{l}\text { Treadle press } \\
\text { Keypeck } \\
\text { Treadle press } \\
\text { Keypeck }\end{array}$ & $\begin{array}{l}26.5 \\
50.7 \\
10.7 \\
93.6\end{array}$ & $\begin{array}{r}10.9 \\
64.5 \\
5.3 \\
101.3\end{array}$ & $\begin{array}{l}37.7 \\
38.1 \\
16.2 \\
99.2\end{array}$ & $\begin{array}{l}74.1 \\
19.6 \\
21.6 \\
56.5\end{array}$ & $\begin{array}{l}39.9 \\
45.0 \\
20.1 \\
104.2\end{array}$ \\
\hline & & \multicolumn{5}{|c|}{ Negative Behavioral Contrast } \\
\hline & & $\begin{array}{l}\text { VI 60-sec } \\
\text { VI 60-sec } \\
\end{array}$ & $\begin{array}{l}\text { VI 60-sec } \\
\text { VI 15-sec }\end{array}$ & $\begin{array}{l}\text { VI } 60-\sec \\
\text { VI } 60-\sec \\
\end{array}$ & $\begin{array}{l}\text { VI } 15-\mathrm{sec} \\
\text { VI } 60-\mathrm{sec} \\
\end{array}$ & $\begin{array}{l}\text { VI } 60-\mathrm{sec} \\
\text { VI } 60-\mathrm{sec}\end{array}$ \\
\hline $\begin{array}{l}83001 \\
17\end{array}$ & $\begin{array}{l}\text { Treadle press } \\
\text { Keypeck } \\
\text { Treadle press } \\
\text { Keypeck }\end{array}$ & $\begin{array}{r}37.6 \\
86.6 \\
23.6 \\
136.5\end{array}$ & $\begin{array}{r}23.0 \\
95.1 \\
16.3 \\
197.2\end{array}$ & $\begin{array}{r}42.2 \\
74.5 \\
43.3 \\
117.0\end{array}$ & $\begin{array}{r}59.8 \\
42.7 \\
302.5 \\
114.4\end{array}$ & \begin{tabular}{r|}
33.8 \\
68.9 \\
163.2 \\
122.2
\end{tabular} \\
\hline & & $\begin{array}{l}\text { VI } 60-\mathrm{sec} \\
\text { VI } 60-\mathrm{sec} \\
\end{array}$ & $\begin{array}{l}\text { VI 15-sec } \\
\text { VI 60-sec } \\
\end{array}$ & $\begin{array}{l}\text { VI 60-sec } \\
\text { VI 60-sec }\end{array}$ & $\begin{array}{l}\text { VI } 60-\mathrm{sec} \\
\text { VI } 15-\mathrm{sec}\end{array}$ & $\begin{array}{l}\text { VI 60-sec } \\
\text { VI } 60-\sec \end{array}$ \\
\hline 83003 & Treadle press & 27.3 & $\begin{array}{l}47.6 \\
98.7\end{array}$ & $\begin{array}{r}39.9 \\
115.5\end{array}$ & $\begin{array}{r}10.4 \\
172.3\end{array}$ & $\begin{array}{l}23.9 \\
86.9\end{array}$ \\
\hline
\end{tabular}



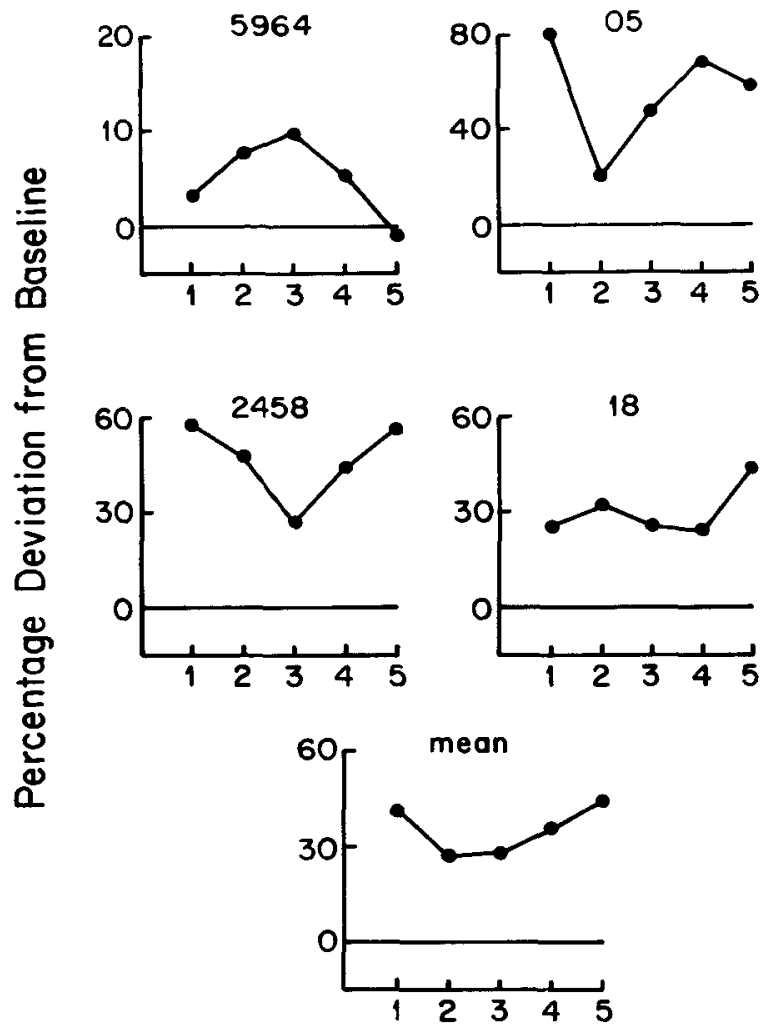

Session Number

Figure 1. Positive keypeck contrast as a function of session number for each subject and for the mean of all subjects. Contrast is mesoured as a percentage devintion, in the constant variable-interval (VI) 60-eec component of the mult VI $4-\mathrm{min}$ VI 60-sec schedele, from the comparable surrounding VI $60-$ sec components of the mult VI 60-sec VI 60-sec schedule.

expressed as a percentage deviation from the surrounding baselines. Points falling below the horizontal line constitute negative behavioral contrast. Points falling above the horizontal line indicate positive induction, defined as an increase in response rates in the constant component following an increase in reinforcement rates in the variable component (McSweeney, 1982).

Table 2 and Figure 3 indicate that negative treadle-press contrast occurred. Fifteen of 15 points for individual subjects and 5 of 5 points for the mean of all subjects fell below the horizontal line. A sign test using the individual subjects' points for the last five sessions the schedule was in effect is significant $(x=0, n=15, p<.002)$.

Figure 4 presents the size of negative keypeck contrast over the last five sessions that the mult VI 15-sec VI 60-sec schedule was in effect. The size of negative keypeck contrast is expressed as a percentage deviation from baseline.

Table 2 and Figure 4 indicate that negative keypeck contrast did not occur consistently. Five of five points for Subject 83003 fell above the horizontal line (positive induction), whereas the points for Subject 17 were not noticeably different from the horizontal line. Negative keypeck contrast occurred for only Subject 83001 . A sign test on the individual subjects' points for the last five sessions the schedule was in effect was not significant $(x=5$, $n=15, p=.075$ ).

\section{DISCUSSION}

As described above, one critical question in the study of behavioral contrast is whether or not positive and negative contrast occur under symmetrical (complementary) conditions. A comparison of Figures 1 and 4 indicates that positive and negative keypeck contrast did not occur consistently under the symmetrical conditions used in the present experiment. Positive keypeck contrast occurred consistently and reliably, whereas negative keypeck contrast occurred for only a single subject.

Comparison of Figures 2 and 3 indicates that positive and negative treadle-press contrast also did not occur under the symmetrical conditions used here. The expression of positive treadle-press contrast seems to depend on the order of schedule presentation. The only consistent observable difference in the treatment and behavior of those pigeons exhibiting and not exhibiting positive treadle-press

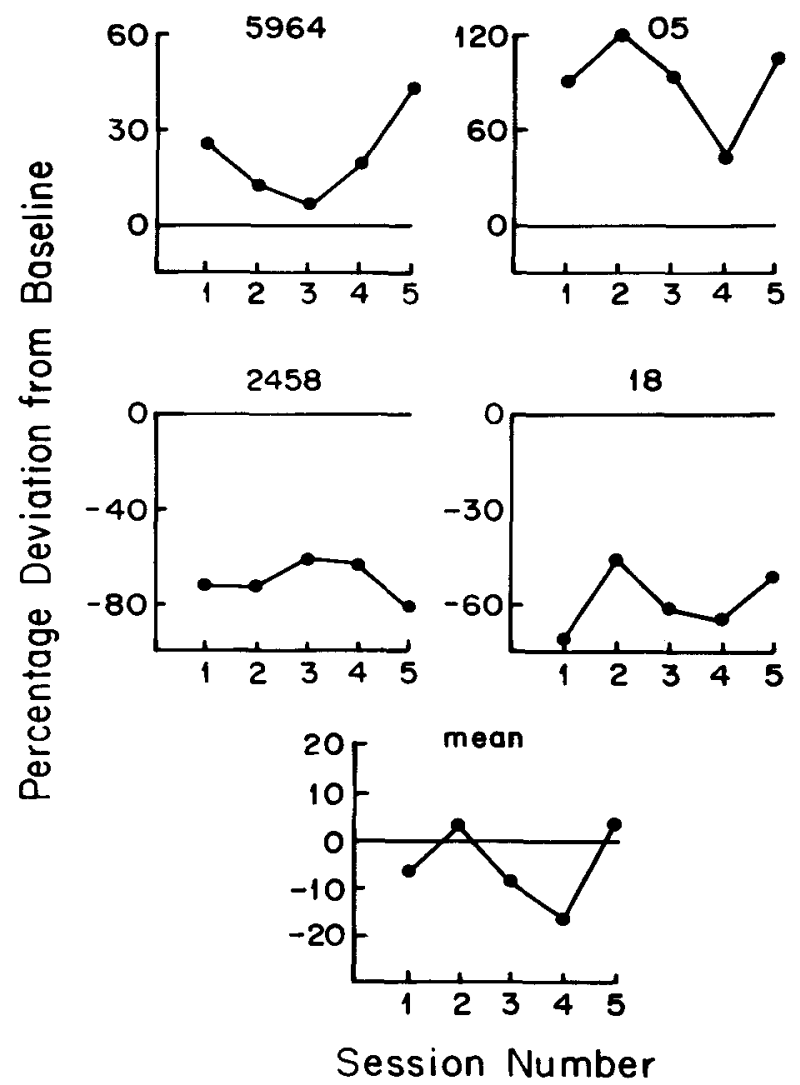

Figure 2. Positive treadle-press contrast as a function of session number for individual subjects and for the mean of all subjects. Contrast was measured in a manner similar to the method used in Figure 1. 

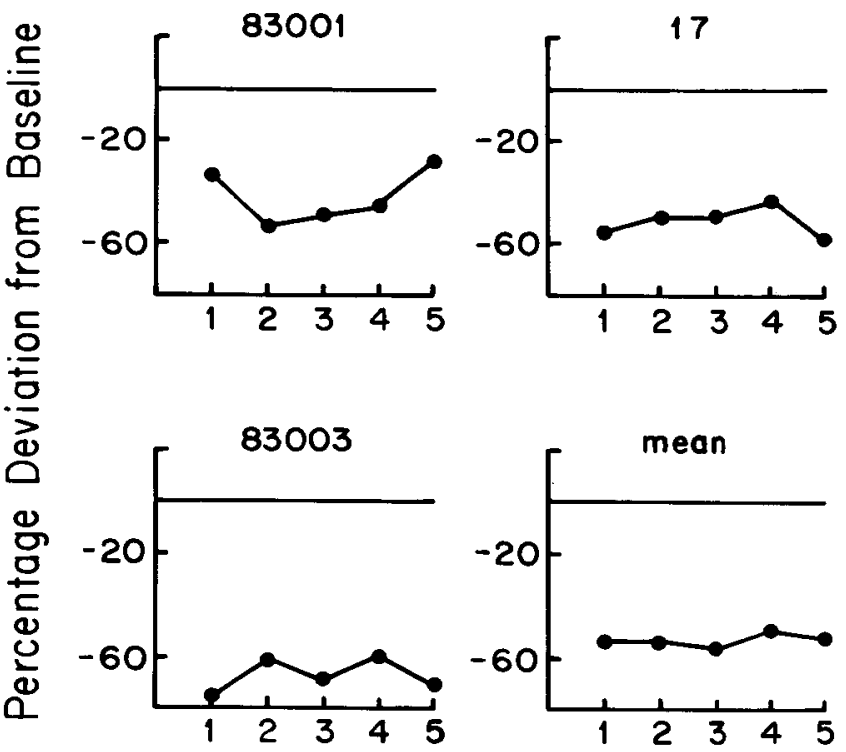

\section{Session Number}

Figure 3. Negative treadle-press contrast as a function of session number for individual subjects and for the mean of all subjects. Contrast is mensured as a percentage deviation, in the constant variableinterval (VI) 60-sec component of the mult VI 6O-sec VI 15-sec schedule, from the comparable surrounding VI 60-sec components of the mult VI 60-sec VI 60-sec schedule. contrast was the order of schedule presentation: Subjects 18 and 2458 did not consistently differ from Subjects 5 and 5964 along the variables of number of sessions to stability, variability of responding during contrast phases, or baseline treadle-press response rates. Therefore, positive treadle-press contrast occurred when subjects were exposed to the positive keypeck contrast condition first, but not when subjects were exposed to the positive treadlepress contrast condition first. However, negative treadlepress contrast occurred consistently in all subjects, regardless of the order of schedule presentation. Therefore, the results indicate that symmetrical conditions are apparently not sufficient to produce positive and negative contrast. These results are consistent with the findings of Ettinger and McSweeney (1981) and Schwartz (1975).

The present results are not consistent with previous research that has found that positive and negative behavioral contrast are symmetrical when the same response produced reinforcers in the two components (McSweeney, 1982; McSweeney et al., 1986). It is possible that the present experimental conditions were not perfectly symmetrical and therefore produced asymmetry between positive and negative contrast. However, this interpretation probably does not account for all of the present results. First, McSweeney et al. (1986, Experiments 2 and 3) utilized a mult VI 60-sec VI 60-sec baseline schedule of reinforcement and a $60-\sec$ component duration similar to
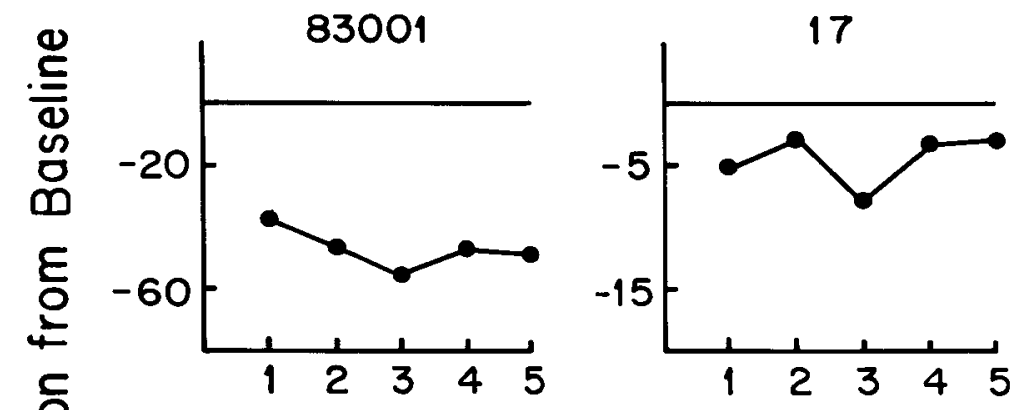

응
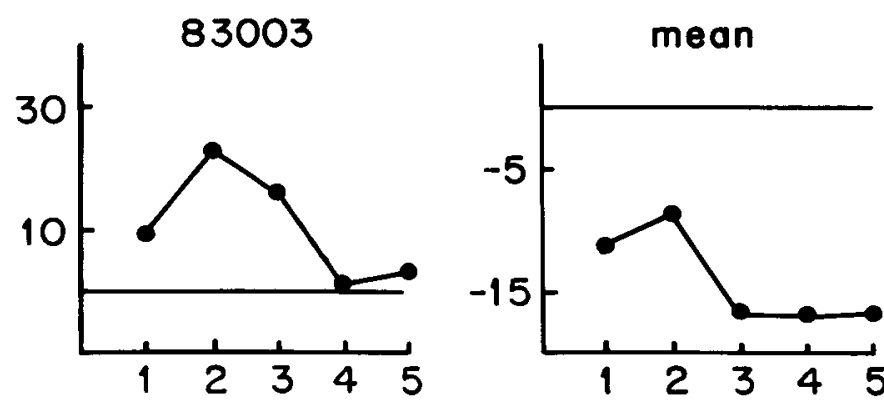

Session Number

Figure 4. Negative keypeck contrast as a function of session number for individual subjects and for the mean of all subjects. Contrast is measured in a manner similar to the method used in Figure 3. 
those used here, but they found positive and negative keypeck contrast that were not significantly different in size. Therefore, the very similar experimental conditions used in the present experiment should have been sufficient to produce symmetrical positive and negative keypeck contrast if keypecking had been the response in both components of the multiple schedule. Second, the results of McSweeney (1982) and McSweeney et al. (1986, Experiment 1) indicate that, when treadle pressing is the required response in both components of a multiple schedule, sizable positive and negative contrast do occur with a $60-\mathrm{sec}$ component duration. Therefore, it is unlikely that the selected component duration extensively biased contrast for one response over the other. However, these previous findings used different baseline reinforcement rates to assess positive and negative treadle-press contrast, and, as mentioned above, baseline reinforcement rates and component duration affect the expression of contrast for the different responses. Therefore, it is possible that the selected baseline reinforcement rate and component duration did have a slight biasing effect on the expression of positive and negative contrast for both response topographies and may have contributed to the intersubject variability of the present results. Further research needs to examine the occurrence and magnitudes of positive and negative contrast as a function of baseline reinforcement rates and component duration when different responses are used in the components of a multiple schedule.

The present results are partially consistent with Staddon's (Hinson \& Staddon, 1978; Staddon, 1982) competition theory of behavioral contrast. Competition theory states that contrast is the result of the interaction of two distinct classes of responding. The first, called terminal responding, occurs when the probability of reinforcement is high. The second, called interim responding, occurs when the probability of reinforcement is low (Staddon \& Simmelhag, 1971). Behavioral contrast results when interim responses are reallocated to the component with the lower reinforcement rate. For example, when the reinforcement rate in one component decreases, terminal responding in that component decreases and interim responding in the other, constant component is reallocated to the variable component. As a result, terminal responding in the constant component increases (positive contrast) because there is more time in the constant component for terminal responding to occur (i.e., disinhibition of terminal responding). Negative contrast occurs in a similar, symmetrical manner. However, different terminal responses (e.g., keypecking and treadle pressing) are assumed to have different sensitivities to reinforcement. Keypecking is assumed to be more sensitive to reinforcement than is treadle pressing because, at a given rate of reinforcement, the response rate for keypecking is higher than the response rate for treadle pressing (Staddon, 1982).

Given the present situation involving keypecking in one component and treadle pressing in the other component of a multiple schedule, competition theory makes the somewhat counterintuitive prediction that the magnitudes of positive and negative treadle-press contrast should be greater than the magnitudes of positive and negative keypeck contrast. Since keypecking is assumed to be more sensitive to reinforcement rate than is treadle pressing, any reinforcement rate will produce higher keypecking response rates than treadle-pressing response rates. As a result, as the rate of keypecking changes, there will be a larger reallocation of interim responding, resulting in larger treadle-press contrast. An example may clarify this point. When the reinforcement rate for treadle pressing is decreased, there will be only a small or moderate change in the time available for interim responding to occur in that component. Therefore, only a small amount of interim responding from the keypeck component can reallocate to the treadle-press component (i.e., there will be a relatively small amount of positive keypeck contrast). However, when the reinforcement rate for keypecking is decreased, there will be a larger increase in the time available for interim responding to occur in that component and, consequently, a larger reallocation of interim responding from the treadle-press component, resulting in larger positive treadle-press contrast. A similar argument for negative contrast results in a greater magnitude of negative treadle-press contrast than of negative keypeck contrast.

The data in Table 2 tend to support the above interpretation. First, for all baseline multiple schedules, the keypeck response rate is higher than the treadle-press response rate, except for Subject 17 during the last baseline schedule. Subject 17 started to peck the treadle during the last two multiple schedules, which accounts for the treadle-press response rate's being higher than the keypeck response rate. Second, during the variable component, the keypeck response rate was always higher than the treadle-press response rate during the comparable component, except for Subject 17, which pecked the treadle during the negative keypeck contrast condition. Third, Figures 2 and 3 indicate that the average magnitude of negative treadle-press contrast is considerably larger than the magnitude of negative keypeck contrast. Finally, if one considers only the two pigeons that exhibited positive treadle-press contrast (Subjects 5 and 5964), then the average magnitude of positive treadlepress contrast is also larger than the average magnitude of positive keypeck contrast.

Competition theory cannot, however, readily explain why two pigeons (Subjects 18 and 2458) did not exhibit positive treadle-press contrast. Furthermore, the theory cannot explain the possible order effect in the occurrence of positive treadle-press contrast. Finally, the theory cannot explain why Subject 17 failed to exhibit sizable negative keypeck contrast, given the large increase in the treadle-press response rate during the negative contrast phase. It must be pointed out, however, that interim responding was not measured during the experiment, and the present results therefore do not represent a direct test of competition theory. Consequently, the above interpretation is tentative. Further research should examine this 
interpretation by replicating the present experiment while explicitly measuring interim responding.

The present results support, and add to, the findings of McSweeney (1983) and McSweeney et al. (1986). Both of those studies found that positive contrast occurs when pigeons press treadles for food reinforcers. Unlike those studies, this present study found that positive treadle-press contrast occurs even when high baseline rates of reinforcement (mult VI 15-sec VI 15-sec) are not used. Although the present results show that high baseline rates of reinforcement are not necessary for the production of positive treadle-press contrast, the two previous studies did find larger and more consistent contrast with a higher rate of reinforcement than was used in this study. Therefore, high rates of reinforcement may produce larger and more consistent contrast when pigeons press treadles for food reinforcers. The finding that high baseline rates of reinforcement produce larger, more consistent positive treadlepress contrast is consistent with competition theory. Increasing the reinforcement rate increases the competitiveness of treadle pressing so that, when the reinforcement rate is later decreased, there is more time available for terminal responding to occur in that component.

In summary, positive keypeck contrast occurred for all pigeons in the positive contrast group, whereas only one pigeon exhibited negative keypeck contrast. Furthermore, all pigeons exhibited negative treadle-press contrast, whereas the expression of positive treadle-press contrast seemed to depend on the order of schedule presentation. The present results also indicate that positive treadle-press contrast does not depend on high baseline rates of reinforcement. Finally, the present results question whether symmetrical theories of positive and negative contrast apply to multiple schedules using different responses in the two components. Further comparative research needs to examine the mechanisms controlling keypecking and treadle pressing when different responses produce reinforcers during multiple schedules.

\section{REFERENCES}

Catania, A. C., Reynolds, G. S. (1968). A quantitative analysis of the responding maintained by interval schedules of reinforcement. Journal of the Experimental Analysis of Behavior, 11, 327-383.

ETtinger, R. H., \& MCSwEENEY, F. K. (1981). Behavioral contrast and responding during multiple food-food, food-water, and water-water schedules. Animal Learning \& Behavior, 9, 216-222.

Hemmes, N. S. (1973). Behavioral contrast in pigeons depends upon the operant. Journal of Comparative \& Physiological Psychology, 85, 171-178.

Herrnstein, R. J. (1970). On the law of effect. Journal of the Experimental Analysis of Behavior, 13, 243-266.

Hinson, J. M., \& Staddon, J. E. R. (1978). Behavioral competition: A mechanism for schedule interactions. Science, 202, 432-434.

Howaro, R. W. (1979). Behavioral contrast in a multiple schedule with topographically different responses. Journal of General Psychology, 101, 265-270.

MCSWEENEY, F. K. (1978a). Negative behavioral contrast on multiple treadle-press schedules. Journal of the Experimental Analysis of Behavior, 29, 463-473.

MCSWEENEY, F. K. (1978b). Prediction of concurrent keypeck treadlepress contrast from simple schedule performance. Animal Learning \& Behavior, 6, 444-450.

McSweeney, F. K. (1982). Positive and negative contrast as a function of component duration for keypecking and treadle pressing. Journal of the Experimental Analysis of Behavior, 37, 281-293.

MCSWEenEY, F. K. (1983). Positive behavioral contrast when pigeons press treadles during multiple schedules. Journal of the Experimental Analysis of Behavior, 39, 149-156.

McSweeney, F. K., Dougan, J. D., Higa, J., \& Farmer, V. (1986). Behavioral contrast as a function of component duration and baseline reinforcement rate. Animal Learning \& Behavior, 14, 173-183.

MCSweEney, F. K., Norman, D. M. (1979). Defining behavioral contrast for multiple schedules. Journal of the Experimental Analysis of Behavior, 32, 457-461.

Rachlin, H. (1973). Contrast and matching. Psychological Review, 80, $217-234$.

SCHWARTZ, B. (1975). Discriminative stimulus location as a determinant of positive and negative contrast in the pigeon. Journal of the Experimental Analysis of Behavior, 23, 167-176.

SCULL, J., \& WeSTBROOK, R. F. (1973). Interactions in multiple schedules with different responses in each of the components. Journal of the Experimental Analysis of Behavior, 20, 511-519.

SIEGEL, S. (1956). Nonparametric statistics for the behavioral sciences. New York: McGraw-Hill.

Staddon, J. E. R. (1982). Behavioral competition, contrast and matching. In M. Commons, R. J. Herrnstein, \& H. Rachlin (Eds.), Quantitative analyses of behavior: Matching and maximizing accounts (pp. 243-261). Cambridge, MA: Ballinger.

Staddon, J. E. R., \& Simmelhag, V. L. (1971). The "superstition" experiment: A re-evaluation of its implications for the principles of adaptive behavior. Psychological Review, 78, 3-43.

WESTBRoOK, R. F. (1973). Failure to obtain positive contrast when pigeons press a bar. Joumal of the Experimental Analysis of Behavior, 20, 499-510.

(Manuscript received July 2, 1986; revision accepted for publication October 29, 1986.) 